\title{
Partial characterization of a novel anti-inflammatory protein from salivary gland extract of Hyalomma anatolicum anatolicum (Acari: Ixodidae) ticks
}

\author{
Mayukh Ghosh ${ }^{1}$, Nirmal Sangwan ${ }^{1}$ and Arun K. Sangwan ${ }^{2}$
}

1. Department of Veterinary Physiology and Biochemistry, College of Veterinary Sciences, Lala Lajpat Rai University of Veterinary and Animal Sciences, Hisar, Haryana, India; 2. Department of Veterinary Parasitology, College of Veterinary Sciences, Lala Lajpat Rai University of Veterinary and Animal Sciences, Hisar, Haryana, India.

Corresponding author: Nirmal Sangwan, e-mail: nirmalsangwan@gmail.com, MG: ghosh.mayukh87@gmail.com, AKS: sangwan_arun@hotmail.com

Received: 22-01-2015, Revised: 16-05-2015, Accepted: 23-05-2015, Published online: 24-06-2015

doi: 10.14202/vetworld.2015.772-776 How to cite this article: Ghosh M, Sangwan N, Sangwan AK (2015) Partial characterization of a novel anti-inflammatory protein from salivary gland extract of Hyalomma anatolicum anatolicum (Acari: Ixodidae) ticks, Veterinary World 8(6):772-776.

\begin{abstract}
Aim: Hyalomma anatolicum anatolicum ticks transmit Theileria annulata, causative agent of tropical theileriosis to cattle and buffaloes causing a major economic loss in terms of production and mortality in tropical countries. Ticks have evolved several immune evading strategies to circumvent hosts' rejection and achieve engorgement. Successful feeding of ticks relies on a pharmacy of chemicals located in their complex salivary glands and secreted saliva. These chemicals in saliva could inhibit host inflammatory responses through modulating cytokine secretion and detoxifying reactive oxygen species. Therefore, the present study was aimed to characterize anti-inflammatory peptides from salivary gland extract (SGE) of $H$. a. anatolicum ticks with a view that this information could be utilized in raising vaccines, designing synthetic peptides or peptidomimetics which can further be developed as novel therapeutics.
\end{abstract}

Materials and Methods: Salivary glands were dissected out from partially fed adult female $H$. a. anatolicum ticks and homogenized under the ice to prepare SGE. Gel filtration chromatography was performed using Sephadex G-50 column to fractionate the crude extract. Protein was estimated in each fraction and analyzed for identification of anti-inflammatory activity. Sodium dodecyl sulfate - polyacrylamide gel electrophoresis (SDS-PAGE) was run for further characterization of protein in desired fractions.

Results: A novel $28 \mathrm{kDa}$ protein was identified in H. a. anatolicum SGE with pronounced anti-inflammatory activity.

Conclusion: Purification and partial characterization of $H$. a. anatolicum SGE by size-exclusion chromatography and SDSPAGE depicted a $28 \mathrm{kDa}$ protein with prominent anti-inflammatory activity.

Keywords: anti-inflammatory, Hyalomma anatolicum anatolicum, size-exclusion chromatography, sodium dodecyl sulfate - polyacrylamide gel electrophoresis, tropical theileriosis.

\section{Introduction}

Ticks are obligatory ectoparasites that exclusively feed on their host blood. Hyalomma anatolicum anatolicum tick is one of the most important ectoparasite of cattle and buffaloes with a wide host range because it acts as a vector of Theileria annulata causing tropical theileriosis [1,2]. Bovine tropical theileriosis, an unapparent infection of indigenous cattle and buffaloes, has emerged as one of the lethal disease of taurine cattle and their crosses especially due to large scale cross-breeding programs [3]. The estimated annual loss in terms of production and mortality in India by T. annulata alone accounts US\$384.3 million [4].

Hence, control of tick infestation stipulates instantaneous consideration and intense research for improved livestock production. Ticks have evolved series of strategies to circumvent host defenses during

Copyright: The authors. This article is an open access article licensed under the terms of the Creative Commons Attributin License (http:// creative commons.org/licenses/by/2.0) which permits unrestricted use, distribution and reproduction in any medium, provided the work is properly cited. their prolonged meal. Among them, secretion of saliva at the attachment site(s) possesses a critical role [5-7]. Despite the host's armor of rejection mechanisms, the tick manages to remain attached and achieve engorgement due to the varied repertoire of pharmacologically active components in their salivary cocktail [8-17]. Related analysis of tick saliva have confirmed about the presence of active anti-inflammatory, antihemostatic/antithrombotic, and immune-modulatory proteins, extracted from saliva and salivary glands of different genera of ticks, that help these arthropods to combat host defense by lowering hosts' B and T-cell responses, altering blood flow, inhibiting inflammation, and thus facilitate the pathogen transmission and infection [18-34].

However, to design effective tick control strategies and tick derived therapeutics, an elaborate knowledge about the tick sialome is required for further development of anti-tick vaccines or synthetic peptide based novel therapeutics. Thus, the present study deals with the proteomic approach to identify and characterize a novel anti-inflammatory protein from salivary gland extract (SGE) of $H$. a. anatolicum ticks. 


\section{Materials and Methods}

\section{Ethical approval}

All the research experiments were conducted after approval of Institutional Animal Ethics Committee.

\section{Collection of ticks}

Semi-fed adult female $H$. a. anatolicum ticks were randomly collected from buffaloes reared by farmers in unorganized cattle farms around the villages of Hisar district, Haryana, India.

\section{Tick dissection and collection of salivary glands}

After washing with normal saline, collected ticks were glued to the bottom of a Petri dish with their dorsal surface upward. Ticks were incised along the dorsal-lateral margin by using fine scalpel blade under a stereoscopic dissection microscope (Magnus MSZ-TR). Non-infected salivary glands were removed by fine tip forceps and transferred into $0.1 \mathrm{M}$ phosphate buffer saline (PBS) ( $\mathrm{pH} 6.0$ ) containing, 5\% glycerol, protease inhibitor cocktail (Sigma, USA), and stored at $-40^{\circ} \mathrm{C}$ until extract preparation [21]. The dissection was performed throughout under ice.

\section{SGE preparation}

The tick salivary glands were homogenized under ice using tissue homogenizer (IKA T10 basic Ultra-Turrax) in $0.1 \mathrm{M} \mathrm{PBS}, \mathrm{pH} 6.0$, containing protease inhibitor cocktail. To remove the tissue debris and particulate materials, the homogenate was centrifuged at $10000 \mathrm{rpm}$ for $15 \mathrm{~min}$ at $4^{\circ} \mathrm{C}$. Then, the clear supernatant was collected and filtered through $0.22 \mu$ syringe filter (MILLEX-GV) and stored at $-40^{\circ} \mathrm{C}$ until further analysis.

Protein purification by gel filtration chromatography

The SGE $(400 \mu 1)$ was applied to Sephadex G-50 (Sigma. USA) gel filtration column $(1 \mathrm{~cm} \times 16 \mathrm{~cm})$ equilibrated with $0.1 \mathrm{M} \mathrm{PBS}, \mathrm{pH}$ 6.0. Elution was performed with the same buffer, collecting fractions of $300 \mu \mathrm{l}$ each. Chromatography was performed at cold chamber, and the column was calibrated with molecular-weight markers from Sigma (alcohol dehydrogenase, $150 \mathrm{kDa}$; albumin, $66 \mathrm{kDa}$; carbonic anhydrase, $29 \mathrm{kDa}$; cytochrome C, $12.4 \mathrm{kDa}$; and the void volume determined with Blue Dextran, $2000 \mathrm{kD})$. The approximate molecular weights of proteins were determined by interpolation with a standard curve of $\mathrm{V}_{\mathrm{e}} / \mathrm{V}_{0}$ against log molecular weight.

\section{Estimation of protein concentration in fractions}

The protein concentration in each fraction was estimated by the method of Lowry et al. [35] using bovine serum albumin (Hi-media) as standard.

\section{Anti-inflammatory activity assay}

The red blood cell (RBC) membrane stabilization has been used as method to study the anti-inflammatory activity in crude extract and isolated fractions [36]. Blood was collected from healthy buffaloes in equal volume of sterilized alsever solution ( $2 \%$ dextrose, $0.8 \%$ sodium citrate, $0.5 \%$ citric acid, and $0.42 \%$ sodium chloride in water) and centrifuged at $3000 \mathrm{rpm}$ for $15 \mathrm{~min}$ at $37^{\circ} \mathrm{C}$. Packed cells were washed with isosaline $(0.85 \%)$ and a $10 \%(\mathrm{v} / \mathrm{v})$ suspension of RBC was made with the same. The assay mixture contained the SGEs $(2,4,8$, and $16 \mu \mathrm{g} / \mathrm{ml}$ protein concentrations), $1 \mathrm{ml}$ of phosphate buffer (0.15 M, pH 7.4), $2 \mathrm{ml}$ of hyposaline (0.36\%) and $0.5 \mathrm{ml}$ of RBC suspension. Instead of hyposaline, $2 \mathrm{ml}$ of distilled water was used in the control. All the assay mixtures were incubated at $37^{\circ} \mathrm{C}$ for $30 \mathrm{~min}$ and centrifuged at $3000 \mathrm{rpm}$ for $15 \mathrm{~min}$ at $37^{\circ} \mathrm{C}$. The hemoglobin content in the supernatant was estimated from $\mathrm{OD}_{560 \mathrm{~nm}}$ using Ultraviolet-visible spectrophotometer (Thermo Scientific Multiskan ${ }^{\circledR}$ Spectrum). The percentage of hemolysis was calculated using the following formula where hemolysis produced in control (distilled water) was assumed to be $100 \%$.

$\%$ Hemolysis $=$ OD of treated sample $\times 100 /$ OD of control

The prevention of hemolysis was taken as a measure of anti-inflammatory activity.

Characterization of peptides on Sodium dodecyl sulfate - polyacrylamide gel electrophoresis (SDS-PAGE)

The peptides in crude extract as well as fractions were further characterized by discontinuous SDS-PAGE (4\% stacking and 15\% resolving gel) using Laemmli buffer system [37] along with Broad Range Protein Molecular-weight Markers (Thermo Scientific, USA). To observe protein bands the gel was silver stained [38]. The molecular weight of peptide bands was interpolated with reference to the standard curve of marker proteins.

\section{Results}

\section{Purification and partial characterization of peptides from tick SGEs}

In preliminary characterization, the crude extract from the tick salivary glands have been fractionated by Sephadex G-50 gel filtration chromatography and protein concentration in each of these fractions is indicated in Figure-1. Electrophoretic pattern of the proteins/peptides in all the fractions shown in Figure-2 clearly depicts 20 prominent protein/peptide bands with molecular weight ranging between $10 \mathrm{kDa}$ and $116 \mathrm{kDa}$. The number and type of peptide bands in first four fractions are similar with a distinct protein band of around $27.8 \mathrm{kDa}$ which is getting very faint in the later fractions (fraction-5 onward). These fractions along with the crude extract were further analyzed for anti-inflammatory activity.

\section{Anti-inflammatory activity in crude extract and iso-} lated fractions

The anti-inflammatory activity was increased with the increase in protein concentration in crude SGEs as well as in fractions. But it did not follow the linear correlation. In $H$. a. anatolicum crude SGE, the anti-inflammatory activity increased from an initial mean value of $15.99 \pm 0.54 \%$ to final value of $24.6 \pm 0.64 \%$ with the increase in protein concentration from $2 \mu \mathrm{g} / \mathrm{ml}$ to $16 \mu \mathrm{g} / \mathrm{ml}$. The anti-inflammatory 


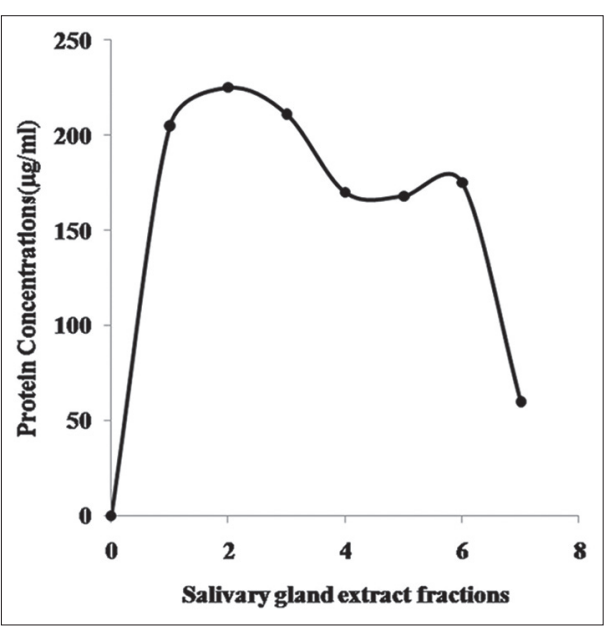

Figure-1: Fractionation of protein/peptides using Sephadex G-50 size-exclusion chromatography from Hyalomma anatolicum anatolicum tick salivary gland extract. Two peaks are centered on fractions 1 and 2 and fractions 5 and 6 . Protein concentration in each of the fractions is also shown.

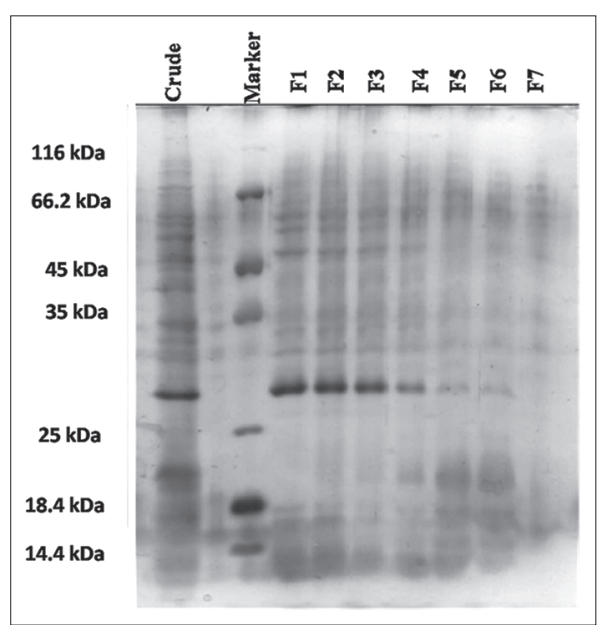

Figure-2: Protein profile of fractionated Hyalomma anatolicum anatolicum tick salivary gland extract characterized by Sodium dodecyl sulfate - polyacrylamide gel electrophoresis on silver stained $15 \%$ acrylamide gel slab. Lane 1 shows the protein profile of crude salivary extract of the tick; lane 3 is the protein molecular marker and the corresponding size of the marker proteins are stated sidewise; lane 4-10 show the protein profile of the gel filtration chromatography fraction 1-7 stated as F1-F7.

activity of the fractions showed similar results (Figure-3). In fraction-1, the anti-inflammatory activity increased from an initial value of $22.98 \%$ to final value of $42.25 \%$ with the increase in protein concentration from $2 \mu \mathrm{g} / \mathrm{ml}$ to $16 \mu \mathrm{g} / \mathrm{ml}$ whereas in fraction-6 it increased from an initial value of $16.92 \%$ to final value of $20.26 \%$. Fraction-1 showed significantly $(\mathrm{p}<0.05)$ higher activity than fraction- 6 at all the different protein concentrations taken which correlates well with the protein $(27.8 \mathrm{kDa})$ concentration shown in SDS-PAGE analysis (Figure-2).

\section{Discussion}

The anti-inflammatory activity reported in fraction- 1 to fraction- 4 of $H$. a. anatolicum SGE is

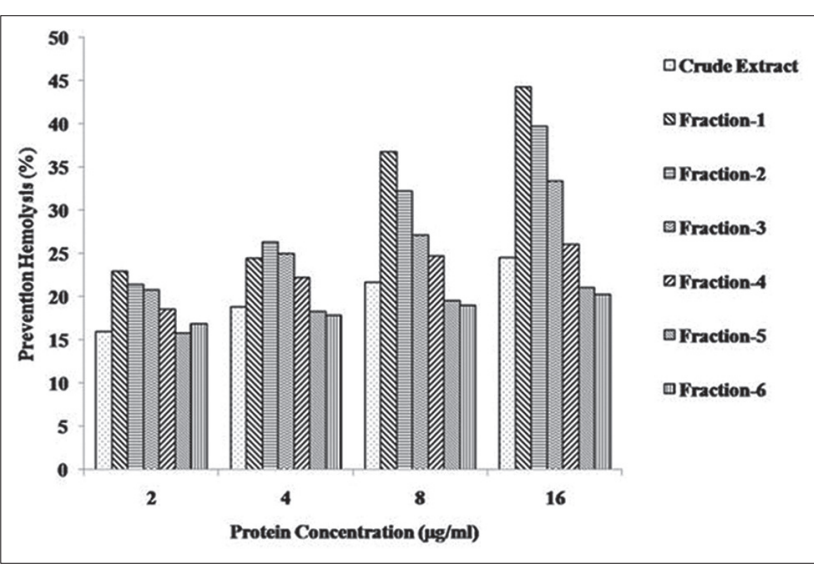

Figure-3: Anti-inflammatory activity in crude salivary gland extracts and gel filtration chromatography fractions of Hyalomma anatolicum anatolicum ticks at different protein concentration.

in accordance with the sialomic analysis in related tick genera, where the conservation of the activity was depicted to satisfy biological demand of the ticks $[13,21,24,39-42]$. The fractions having anti-inflammatory activity showed a positive correlation with the concentrations of total protein in those fractions. All the fractions having anti-inflammatory activity had the common protein with molecular weight of $27.8 \mathrm{kDa}$. Furthermore, the electrophoretic profile revealed more pronounced protein band in fraction-1 having anti-inflammatory activity as compared to the bands in fraction- 5 and 6 where the activity was less. The protein was almost absent in fraction-7 with negligible activity. The SDS-PAGE also showed the low molecular weight peptide bands which appeared in the first four fractions and could be due to denaturation of multimeric proteins which have got denatured during SDS treatment. It has been reported that the anti-inflammatory activity in the tick Ixodes scapularis, the vector of Lyme disease or Borreliosis, to affect the host proteolytic activity in the sites of infestation was mainly through the release of sialostatin $\mathrm{L}$ inhibited proliferation of cytotoxic T lymphocytes [20]. It has been found that Borrelia pathogens exploit tick saliva to facilitate their transmission by repressing host innate immunity and cutaneous inflammation [40]. The presence of two families of immunomodulatory peptides (hyalomin-A and -B) were identified by $\mathrm{Wu}$ et al. [21] from the salivary glands of the hard tick $H$. a. asiaticum having molecular weights of only 1231.16 and 3688.2 Dalton. These two peptides were also found to suppress host inflammatory response by modulating cytokine secretion and detoxifying reactive oxygen species. Hence, the anti-inflammatory activity may have a relation with other modes of defense mechanisms in ticks. The experiment of Vancova et al. [39] and Déruaz et al. [14] depicted the presence of Evasin-3 and Evasin-4 like anti-chemokine activity in SGEs of Rhipicephalus sanguineus ticks. Evasin-3 was found to be important in controlling neutrophils during blood-feeding and 
its conservation among metastriate ixodid tick species. Use of molecular dynamics simulations depicted a competition for histamine binding between hosts' native histamine receptor and the secreted tick salivary lipocalin where histamine choose the later with more affinity [28]. Several members of serine protease inhibitor (serpin) were identified in Rhipicephalus (Boophilus) Microplus, which are essential for blood coagulation, fibrinolysis, inflammation, and complement activation [31]. Proteomic and transcriptomic insight into Dermacentor andersoni saliva also explored numerous bioactive molecules including inflammation inhibitors [43]. Anti-inflammatory activity was also observed in Ixodes ricinus saliva where serpin IRS2 inhibits Th17 differentiation and impairs interleukin-6 (IL-6)/STAT-3 signaling pathway [44]. Serpins were also identified and analyzed in Amblyomma americanum, both male and female ticks. The female serpins were found to be conserved across taxa [45]. This related knowledge about tick sialome provides an overview about the conservation and potential of tick salivary anti-inflammatory proteins across the genera, modulating host immune response. It also corroborate with our finding about $H$. a. anatolicum salivary anti-inflammatory activity in the recent study. These also provide an account of versatility and redundancy of pharmacologically active candidates in tick salivary cocktail and indicate that the anti-inflammatory activity may also have role in saliva activated pathogen transmission of $T$. annulata by $H$. a. anatolicum ticks as future prospect of the present study. Though it was a preliminary study regarding $H$. a. anatolicum sialome, further research is needed in this field to enlighten the mechanisms and pathways of these pharmacologically active salivary gland proteins which will be helpful in controlling ticks and tick-borne diseases.

\section{Authors' Contributions}

NS designed the experiment, data analyses and final corrections of the manuscript. MG and AKS collected the sample. AKS identified the tick species and contributed in the dissection of ticks. MG performed the dissection of ticks, wet lab analyses, and data analyses. All authors participated in manuscript preparation. All authors read and approved the final manuscript.

\section{Acknowledgments}

This research was supported partly with grants from University Grant Commission, Govt. of India.

\section{Competing Interests}

The authors declare that they have no competing interests.

\section{References}

1. Brown, C.G.D. (1997) Dynamics and impact of tick borne diseases of cattle. Trop. Anim. Health Prod., 29 Suppl 4: 1-3. 2. Preston, P.M. (2001) The Encyclopedia of Arthropod
Transmitted infections. $1^{\text {st }}$ ed. CABI Publishing, Wallingford (UK). p487-504.

3. ICAR Vision 2030. (2011) Project Director, Directorate of Knowledge Management in Agriculture. Indian Council of Agricultural Research, Krishi Anusandhan Bhavan, Pusa, New Delhi.

4. Minjauw, L. and McLeod, A. (2003) Tick borne diseases and poverty. The impact of tick and tick borne diseases on the livelihoods of small-scale and marginal livestockowners in India and eastern and southern Africa. In: Research Report. DFID Animal Health Programme. UK: Centre for Tropical Veterinary Medicine, University of Edinburgh.

5. Ribeiro, J.M.C. and Francischetti, I.M.B. (2003) Role of arthropod saliva in blood feeding: Sialome and post-sialome perspectives. Annu. Rev. Entomol., 48: 7388.

6. Islam, M.K., Tsuji, N., Miyoshi, T., Alim, M.A., Huang, X., Hatta, T. and Fujisaki, K. (2009) The Kunitz-like modulatory protein haemangin is vital for hard tick blood-feeding success. PLoS Pathog., 5: e1000497.

7. Fontaine, A., Diouf, I., Bakkali, N., Missé, D., Pagès, F., Fusi, T., Rogier, C. and Almeras, L. (2011) Implication of haematophagous arthropod salivary proteins in host-vector interactions. Parasit. Vectors, 4: 187.

8. Guo, X., Booth, C.J., Paley, M.A., Wng, X., De Ponte, K., Fikrig, E., Narasimhan, S. and Montgomery, R.R. (2009) Inhibition of neutrophil function by two tick salivary proteins. Infect. Immun., 77: 2320-2329.

9. Randolph, S.E. (2009) Tick-borne disease systems emerge from the shadows: The beauty lies in molecular detail, the message in epidemiology. Parasitology, 136: 1403-1413.

10. Mori, A., Konnai, S., Yamada, S., Hidano, A., Murase, Y., Ito, T., Takano, A., Kawabata, H., Onuma, M. and Ohashi, K. (2010) Two novel salp15-like immunosuppressant genes from salivary glands of ixodespersulcatus schulze tick. Insect. Mol. Biol., 19: 359-365.

11. Francischetti, I.M.B., Sá-Nunes, A, Mans, B.J, Santos, I.M. and Ribeiro, J.M.C. (2009) The role of saliva in tick feeding. Front Biosci., 14: 2051-2088.

12. Anisuzzaman, M., Islam, M.K., Alim, M.A., Miyoshi, T., Hatta, T., Yamaji, K., Matsumoto, Y., Fujisaki, K. and Tsuji, N. (2011) Longistatin, a plasminogen activator, is key to the availability of blood-meals for ixodid ticks. PLoS Pathog., 7: e1001312.

13. Kazimírová, M. and Štibrániová, I (2013) Tick salivary compounds: their role in modulation of host defences and pathogen transmission. Front Cell Infect. Microbiol., 3: 43.

14. Déruaz, M., Bonvin, P., Severin, I.C., Johnson, Z., Krohn, S., Power, C.A. and Proudfoot, A.E.I. (2013) Evasin-4, a tick-derived chemokine-binding protein with broad selectivity can be modified for use in preclinical disease models. FEBS. J., 280: 4876-4887.

15. Tirloni, L., Reck, J., Terra, R.M.S., Martins, J.R., Mulenga, A., Sherman, N.E., Fox, J.W., Yates, J.R. $3^{\text {rd., }}$ Termignoni, C., Pinto, A.F. and Vaz Ida S, Jr. (2014) Proteomic analysis of cattle tick Rhipicephalus (Boophilus) microplus saliva: A comparison between partially and fully engorged females. PLoS One, 9(4): e94831.

16. Radulović ŽM, Kim TK, Porter LM, Sze SH, Lewis L, Mulenga A. (2014) A 24-48 h fed Amblyomma americanum tick saliva immuno-proteome. BMC Genomics, 15(1): 518.

17. Garcia, G.R., Gardinassi, L.G., Ribeiro, J.M.C., Anatriello, E., Ferreira, B.R., Moreira, H.N.S., Mafra, C., Martins, M.M., Szabó, M.P.J., de Miranda-Santos, I.K.F. and Maruyama, S.R. (2014) The sialotranscriptome of Amblyomma triste, Amblyomma parvum and Amblyomma cajennense ticks, uncovered by 454-based RNA-seq. Parasit Vectors, 7(1): 430.

18. Paesen, G.C., Adams, P.L., Harlos, K., Nuttall P.A. and Stuart, D.I. (1999) Tick histamine-binding proteins: Isolation, cloning, and three-dimensional structure. Mol. Cell, 3: 661-671.

19. Leboulle, G., Crippa, M., Decrem, Y., Mejri, N., Brossard M., 
Bollen A. and Godfroid, E. (2002) Characterization of a novel salivary immunosuppressive protein from ixodes ricinus ticks. J. Biol. Chem., 277: 10083-10089.

20. Kotsyfakis, M., Sa-Nunes, A., Francischetti, I.M.B., Mather, T.N., Andersen, J.F. and Ribeiro, J. M.C. (2006) Antiinflammatory and immunosuppressive activity of sialostatin L, a salivary cystatin from the tick Ixodes scapularis. J Biol Chem., 281: 26298-26307.

21. Wu, J., Wang, Y., Liu, H., Yang, H., a, D., Li, J., Li, D., Lai, R. and Yu, H. (2010) Two immunoregulatory peptides with antioxidant activity from tick salivary glands. J. Biol. Chem., 285(22): 1-19.

22. Kaufman, R. (2010) Ticks: Physiological aspects with implications for pathogen transmission. Ticks Tick Borne Dis., 1: 11-22.

23. Fialová, A., Cimburek, Z., Iezzi, G. and Kopecký, J. (2010) Ixodes ricinus tick saliva modulates tick-borne encephalitis virus infection of dendritic cells. Microbes Infect., 12: $580-585$.

24. Chmelar, J., Oliveira, C.J., Rezacova, P., Francischetti, I.M.B., Kovarova, Z., Pejler, G., Kopacek, P., Ribeiro, J.M.C., Mares, M., Kopecky, J. and Kotsyfakis, M. (2011) A tick salivary protein targets cathepsin G and chymase and inhibits host inflammation and platelet aggregation. Blood, 117: 736-744.

25. Schuijt, T.J., Coumou, J., Narasimhan, S., Dai, J., Deponte, K., Wouters, D., Brouwer, M., Oei, A., Roelofs, J.J., van Dam, A.P., van der Poll, T., Van't Veer, C., Hovius, J.W. and Fikrig, E. (2011) A tick mannose-binding lectin inhibitor interferes with the vertebrate complement cascade to enhance transmission of the Lyme disease agent. Cell Host Microbes, 10: 136-146.

26. Randolph, S.E. (2011) Transmission of tick-borne pathogens between co-feeding ticks: Milan labuda's enduring paradigm. Ticks Tick Borne Dis., 2: 179-182.

27. Radolf, J.D., Caimano, M.J., Stevenson, B. and Hu, L.T. (2012) Of ticks, mice and men: Understanding the dual-host lifestyle of Lyme disease spirochaetes. Nat. Rev. Microbiol., 10: 87-99.

28. Valdes, J.J. (2014) Antihistamine response: A dynamically refined function at the host-tick interface. Parasit Vectors, 7(1): 491.

29. Ghosh, M., Sangwan, N. and Sangwan, A.K. (2014) Variations in free radical scavenging activities and antioxidant responses in salivary glands of Hyalomma anatolicum anatolicum and Hyalomma dromedarii (Acari: Ixodidae) ticks. Vet. World, 7(10): 876-881.

30. Oliveira, C.J., Anatriello, E., de Miranda-Santos, I.K., Francischetti, I.M., Sá-Nunes, A., Ferreira, B.R. and Ribeiro, J.M.C. (2013) Proteome of Rhipicephalus sanguineus tick saliva induced by the secretagogues pilocarpine and dopamine. Ticks Tick Borne Dis., 4(6): 469-477.

31. Tirloni, L., Seixas, A., Mulenga, A., da Silva, VI Jr., Termignoni, C. (2014) A family of serine protease inhibitors (serpins) in the cattle tick Rhipicephalus (Boophilus) microplus. Exp. Parasitol., 137: 25-34.

32. Cotte, V., Sabatier, L., Schnell, G., Carmi-Leroy, A., Rousselle, J.C., Arsene-Ploetze, F., Malandrin, L., Sertour, N., Namane, A., Ferquel, E. and Choumet, V.
(2014) Differential expression of Ixodes ricinus salivary gland proteins in the presence of the Borrelia burgdorferi sensu lato complex. J. Proteomics, 96: 29-43.

33. Lewis, L.A., Radulović, Z.M., Kim, T.K., Porter, L.A. and Mulenga, A. (2015) Identification of 24h Ixodes scapularis immunogenic tick saliva proteins. Ticks Tick Borne Dis., 6(3): 424-434.

34. Tan, A.W., Francischetti, I.M., Slovak, M., Kini, R.M. and Ribeiro, J.M.C. (2015) Sexual differences in the sialomes of the zebra tick, Rhipicephalus pulchellus. J. Proteomics, 117: 120-144.

35. Lowry, O.H., Rosebrough, N.J., Farr, A.L. and Randall, R.J. (1951) Potein measurement with the folin phenol reagent. $J$. Biol. Chem., 193: 265-275.

36. Shinde, U.A., Phadke, A.S., Nair, A.M., Mungantiwar, A.A., Dikshit, V.J. and Saraf, V.O. (1999) Membrane stabilizing activity-a possible mechanism of action for the anti-inflammatory activity of Cedrus deodara wood oil. Fitoterapia, 70: 251-257.

37. Laemmli, U.K. (1970) Cleavage of structural proteins during the assembly of the head of bacteriophage T4. Nature, 227: 680-685.

38. Morrissey, J.H. (1981) Silver stain for proteins in polyacrylamide gels: A modified procedure with enhanced uniform sensitivity. Anal. Biochem., 117: 307-310.

39. Vancova, I., Hajnická, V., Slovák, M., Kocáková, P., Paesen, G.C. and Nutall, P.A. (2010) Evasin-3-like anti-chemokine activity in salivary gland extracts of ixodid ticks during blood-feeding: A new target for tick control. Parasite Immunol., 32: 460-463.

40. Kern, A., Collin, E., Barthel, C., Michel, C., Jaulhac, B. and Boulanger, N. (2011) Tick saliva represses innate immunity and cutaneous inflammation in a murine model of lyme disease. Vector Borne Zoonotic Dis., 11: 1343-1350.

41. Oliveira, C.J., Sa-Nunes, A., Francischetti, I.M., Carregaro, V., Anatriello, E., Silva, J.S., Santos, I.K., Ribeiro, J.M.C. and Ferreira, B.R. (2011) Deconstructing tick saliva: Non-protein molecules with potent immunomodulatory properties. J. Biol. Chem., 286: 10960-10969.

42. Chmelar, J., Calvo, E., Pedra, J.H.F., Francischetti, I.M.B. and Kotsyfakis, M. (2012) Tick salivary secretion as a source of antihemostatics. J. Proteomics, 75: 3842-3854.

43. Mudenda, L., Pierlé, S.A., Turse, J.E., Scoles, G.A., Purvine, S.O., Nicora, C.D., Clauss, T.R., Ueti, M.W., Brown, W.C. and Brayton, K.A. (2014) Proteomics informed by transcriptomics identifies novel secreted proteins in Dermacentor andersoni saliva. Int J Parasitol., 44(13): 1029-37.

44. Páleníková, J., Lieskovská, J., Langhansová, H., Kotsyfakis, M., Chmelař, J., Kopecký, J. (2015) Ixodes ricinsus salivary Serpin IRS-2 Affects Th17 differentiation via inhibition of the interleukin-6/STAT-3 signaling pathway. Infect. Immun., 83(5): 1949-56.

45. Porter, L., Radulović, Ž., Kim, T., Braz, G.R., Da Silva Vazm, I, Jr. and Mulenga, A. (2015) Bioinformatic analyses of male and female Amblyomma americanum tick expressed serine protease inhibitors (serpins). Ticks Tick Borne Dis., 6(1): 16-30. 